\title{
Melatonin Analogue Antiproliferative and Cytotoxic Effects on Human Prostate Cancer Cells
}

\author{
Angela Calastretti ${ }^{1,+}$, Giuliana Gatti ${ }^{1,+}{ }^{\dagger}$, Valeria Lucini ${ }^{2}$, Silvana Dugnani ${ }^{2}$, Gianfranco Canti ${ }^{1}$,

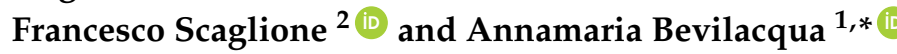 \\ 1 Department of Medical Biotechnology and Translational Medicine, Università degli Studi di Milano, \\ 20122 Milan, Italy; luisa.calastretti@unimi.it (A.C.); giuliana.gatti@unimi.it (G.G.); \\ gianfranco.canti@unimi.it (G.C.) \\ 2 Department of Oncology and Hemato-oncology, Università degli Studi di Milano, 20122 Milan, Italy; \\ valeria.lucini@unimi.it (V.L.); silvana.dugnani@unimi.it (S.D.); francesco.scaglione@unimi.it (F.S.) \\ * Correspondence: annamaria.bevilacqua@unimi.it; Tel.: +39-02-50317008 \\ + These authors contributed equally to this work.
}

Received: 29 April 2018; Accepted: 16 May 2018; Published: 18 May 2018

\begin{abstract}
Melatonin has been indicated as a possible oncostatic agent in different types of cancer, its antiproliferative role being demonstrated in several in vitro and in vivo experimental models of tumors. Specifically, melatonin was proven to inhibit cell growth of both androgen-dependent and independent prostate cancer cells, through various mechanisms. A number of melatonin derivatives have been developed and tested for their role in the prevention and treatment of neoplastic diseases. We recently proved the in vitro and in vivo anticancer activity of UCM 1037, a newly-synthetized melatonin analogue, on melanoma and breast cancer cells. In this study we evaluated UCM 1037 effects on cell proliferation, cell cycle distribution, and cytotoxicity in LNCaP, PC3, DU145, and 22Rv1 prostate cancer cells. We demonstrated significant dose- and time-dependent UCM 1037 antiproliferative effects in androgen-sensitive LNCaP and 22Rv1 cells. Data from flow cytometric studies suggest that UCM 1037 is highly cytotoxic in androgen-sensitive prostate cancer cells, although no substantial increase in the apoptotic cell fraction has been observed. UCM 1037 cytotoxic effects were much less evident in androgen-insensitive PC3 and DU145 cells. Experiments performed to gain insights into the possible mechanism of action of the melatonin derivative revealed that UCM 1037 down-regulates androgen receptor levels and Akt activation in LNCaP and 22Rv1 cells.
\end{abstract}

Keywords: melatonin analogues; melatonin receptors; anti-cancer drugs; prostate cancer; androgen receptor; Akt

\section{Introduction}

Melatonin is an indolic hormone which plays pleiotropic roles and is widely distributed in most living organisms, where it is involved in various physiological functions [1]. In mammals, melatonin is recognized as the key regulator of the circadian rhythm and is largely secreted by the pineal gland in response to darkness [2]. However, many other organs or cells producing melatonin have been identified, including the gastrointestinal tract, skin, reproductive tract, and immune system cells [3]. The relevance of melatonin has been demonstrated in human physiology and pathology, due to its anti-inflammatory properties, antioxidant action, and its role in immunomodulation, energy metabolism, and hematopoiesis.

Furthermore, a number of epidemiological studies support a protective role of melatonin in both hormone-dependent and hormone-independent cancers, suggesting an inverse correlation between melatonin level and cancer incidence [4]. Specifically, two case-control studies were conducted on 
prostate cancer patients indicating that men with urinary melatonin levels below the median had a statistically significant increased risk to develop advanced disease compared with men with levels above the median $[5,6]$.

Melatonin has oncostatic properties in different in vitro and in vivo experimental models of neoplasia [7]. The effects of melatonin are mediated by both receptor-dependent and receptor-independent mechanisms. Melatonin receptors include plasma membrane and nuclear binding sites. Two membrane receptors, $\mathrm{MT}_{1}$ and $\mathrm{MT}_{2}$, belonging to the family of guanine nucleotide-binding regulatory protein ( $G$ protein)-coupled receptors, have been characterized in mammals [8]. $\mathrm{MT}_{1}$ activation leads to diverse responses, most of them acting on cAMP signaling and the calcium-calmodulin pathway, although the signal transduction pathways response varies among different tissues and cell types [9]. Binding of melatonin to $\mathrm{MT}_{2}$ receptors triggers a number of signal transduction pathways including phosphoinositide production, the inhibition of adenylyl cyclase and the inhibition of soluble guanylyl cyclase pathway [10]. Both membrane receptors can also activate other signaling pathways involved in multiple regulatory processes, including phospholipase $\mathrm{C}$ /protein kinase $\mathrm{C}$, mitogen-activated protein kinases, and extracellular-signal-regulated kinase pathways $[3,11]$. Melatonin receptors have been detected in numerous tissues and are widely distributed in the body [12].

$\mathrm{MT}_{1}$ and $\mathrm{MT}_{2}$ expression was also shown in human prostate cancer cells [13,14]; however, there is still controversy regarding the exact role of these receptors in melatonin-mediated protection against prostate cancer progression. Melatonin receptor-independent mechanisms have been demonstrated in prostate cancer suggesting a scenario where the indole triggers signaling cascades that ultimately hamper prostate cancer cell growth [7].

Several melatonin derivatives have been recently developed and tested for their role in the prevention or treatment of neoplastic diseases, either alone or in combination with other drugs to improve the sensitivity of cancers to inhibition by conventional drugs, and to reduce side-effects $[15,16]$. We previously characterized a number of melatonin receptor ligands and we demonstrated the in vitro and in vivo anticancer activity of newly-synthetized melatonin analogues on melanoma and breast cancer cells [17]. In particular, UCM 1037 melatonin derivative demonstrated significant antiproliferative effect in DX3, WM-115, MCF-7, and MDA-MB231 cells; the flow cytometric analysis also confirmed the cytotoxic activity of UCM 1037 on the same cell lines. The anti-tumor activity of UCM 1037 was also demonstrated in vivo in a melanoma xenograft mice model.

In this paper, UCM 1037 melatonin analogue effects were evaluated in different prostate cancer cell lines. We examined the effects of the molecule on cell proliferation, cell cycle distribution, and cytotoxicity. Experiments were also performed to gain insights into the possible mechanism of action of the melatonin derivative and its crosstalk with the androgen signaling pathway.

\section{Results}

\subsection{Expression of Melatonin Receptors in Prostate Cancer Cells}

In order to evaluate the antiproliferative role of the previously characterized melatonin analogue UCM 1037 (Figure 1) on human prostate cancer cells, four cell lines were selected.

We chose both androgen-sensitive, namely LNCaP and 22Rv1, and androgen-insensitive, such as DU145 and PC3, prostate cancer cells. $\mathrm{MT}_{1}$ and $\mathrm{MT}_{2}$ protein levels were analyzed by Western blotting in these cell lines. $\mathrm{MT}_{1}$ receptor was detectable in all the cell lines examined (Figure $2 \mathrm{~A}$ ). $\mathrm{MT}_{1}$ levels were highest in LNCaP cells, intermediate in DU145, and lowest in 22Rv1 and PC3 cells (Figure 2B). In contrast, $\mathrm{MT}_{2}$ protein expression was evident only in PC3 and DU145 cell lines. Androgen receptor (AR) expression was confirmed in androgen-sensitive LNCaP and 22Rv1 cells. 


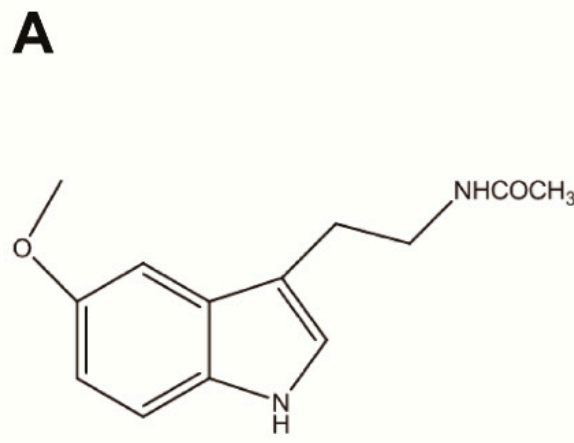

MLT

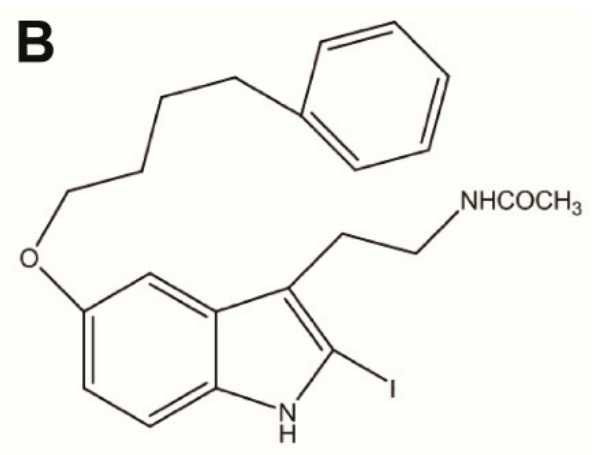

UCM 1037

Figure 1. Chemical structures of melatonin (MLT) (A) and its synthetic derivative UCM 1037 (B).
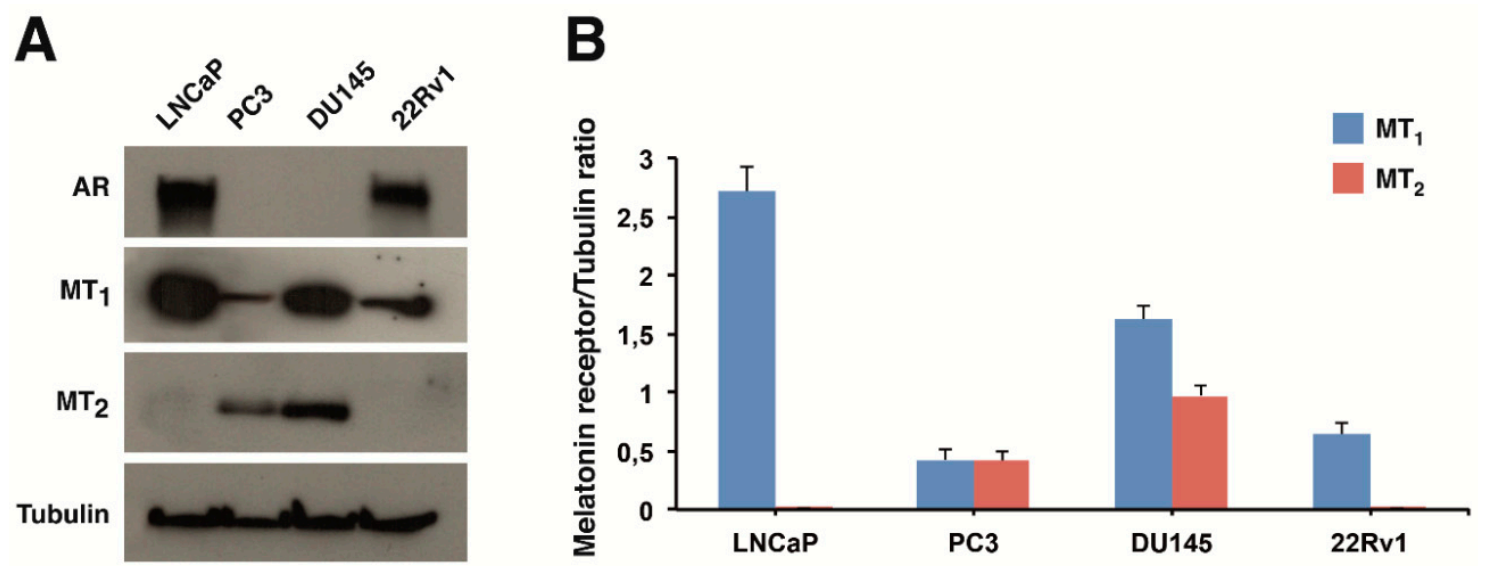

Figure 2. $\mathrm{AR}, \mathrm{MT}_{1}$, and $\mathrm{MT}_{2}$ protein levels in prostate cancer cell lines. (A) Western blot showing the expression of $\mathrm{AR}, \mathrm{MT}_{1}$, and $\mathrm{MT}_{2}$ in $\mathrm{LNCaP}, \mathrm{PC} 3, \mathrm{DU} 145$, and 22Rv1 cells. Tubulin is shown as a loading control. One representative blot is shown of three independent experiments; (B) densitometry of $\mathrm{MT}_{1}$ and $\mathrm{MT}_{2}$ protein expression. Bar charts show quantification of $\mathrm{MT}_{1}$ (blue bars) and $\mathrm{MT}_{2}$ (red bars) normalized versus tubulin in prostate cancer cell lines. Each bar represents the mean \pm standard deviation (s.d.) of three independent experiments.

\subsection{Melatonin Analogue Effects on Prostate Cancer Cell Growth}

The antiproliferative effects of UCM 1037 melatonin analogue were evaluated by a cell counting assay that detects cellular metabolic activities. LNCaP, PC3, DU145, and 22Rv1 cells were seeded in 96-well plates, and $24 \mathrm{~h}$ later cells were treated with UCM $1037\left(10^{-6}-10^{-4} \mathrm{M}\right)$ or with melatonin $\left(10^{-5}-10^{-3} \mathrm{M}\right)$ dissolved in $0.1 \%$ dimethyl sulfoxide (DMSO) for 24,48 , and $72 \mathrm{~h}$. As a control, $0.1 \%$ DMSO was also administered to cell culture for the same exposure times. The cell viability assay revealed that UCM 1037 had an antiproliferative effect in a dose- and time-dependent manner (Figures 3 and 4). In particular, UCM $103710^{-4} \mathrm{M}$ showed the maximum effect in androgen-sensitive cells, reducing LNCaP and 22Rv1 cell number to $38 \%$ and $31 \%$ after $48 \mathrm{~h}$ and to $34 \%$ and $14 \%$ after $72 \mathrm{~h}$, respectively, compared to DMSO-treated cells (Figure 3A,B).

The melatonin analogue caused a less pronounced decrease in cell proliferation in androgen-insensitive prostate cancer cells, UCM $103710^{-4} \mathrm{M}$ reducing cell number to $80 \%$ and $73 \%$ after $48 \mathrm{~h}$ and to $68 \%$ and $67 \%$ after $72 \mathrm{~h}$ in PC3 and DU145 cells, respectively, compared to DMSO-treated cells (Figure 4A,B). Melatonin did not significantly inhibit prostate cancer cell proliferation at the same dose. 

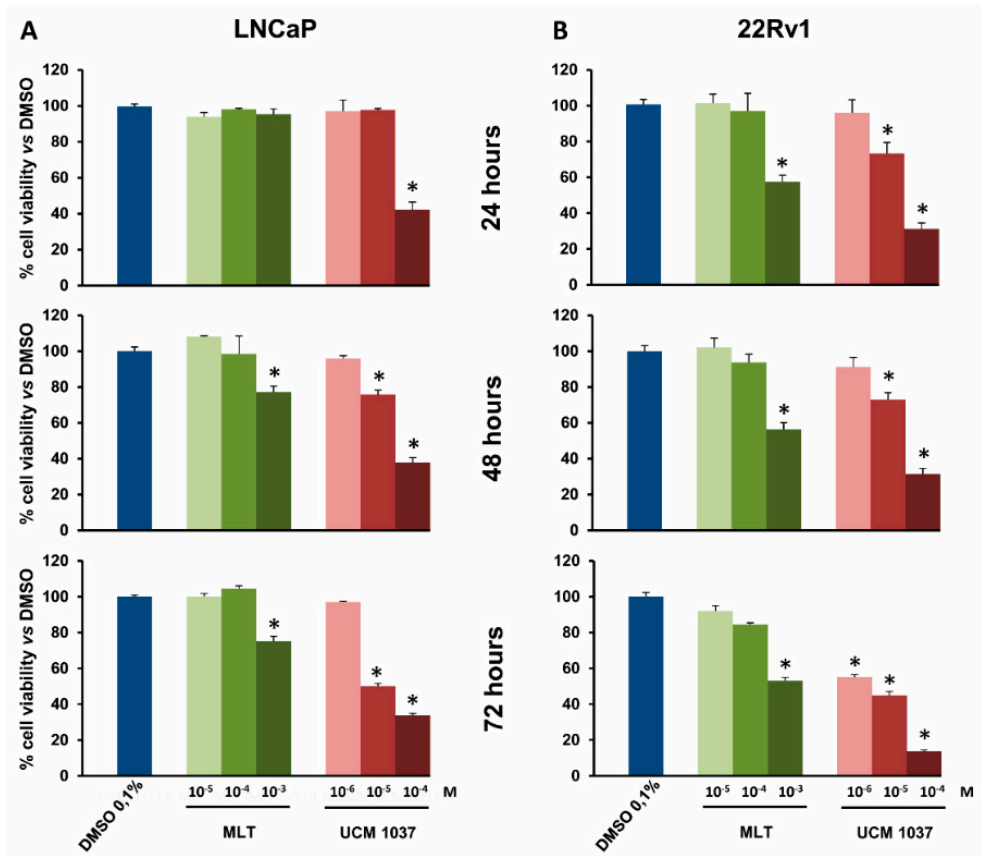

Figure 3. Cell viability of androgen-sensitive prostate cancer cells treated with melatonin and UCM 1037. LNCaP and 22Rv1 androgen-sensitive prostate cancer cells were treated with melatonin (MLT) or with UCM 1037 at the indicated doses expressed in molarity (M), as described in the Materials and Methods. LNCaP (A) and 22Rv1 (B) cell viability was evaluated after 24, 48, and $72 \mathrm{~h}$. Graphic bars represent the percentage of viable cells in each sample. The results have been normalized to $0.1 \%$ DMSO-treated cells and are the means of three independent experiments \pm s.d. ${ }^{*} p$-value $<0.001$ versus $0.1 \%$ DMSO-treated cells.
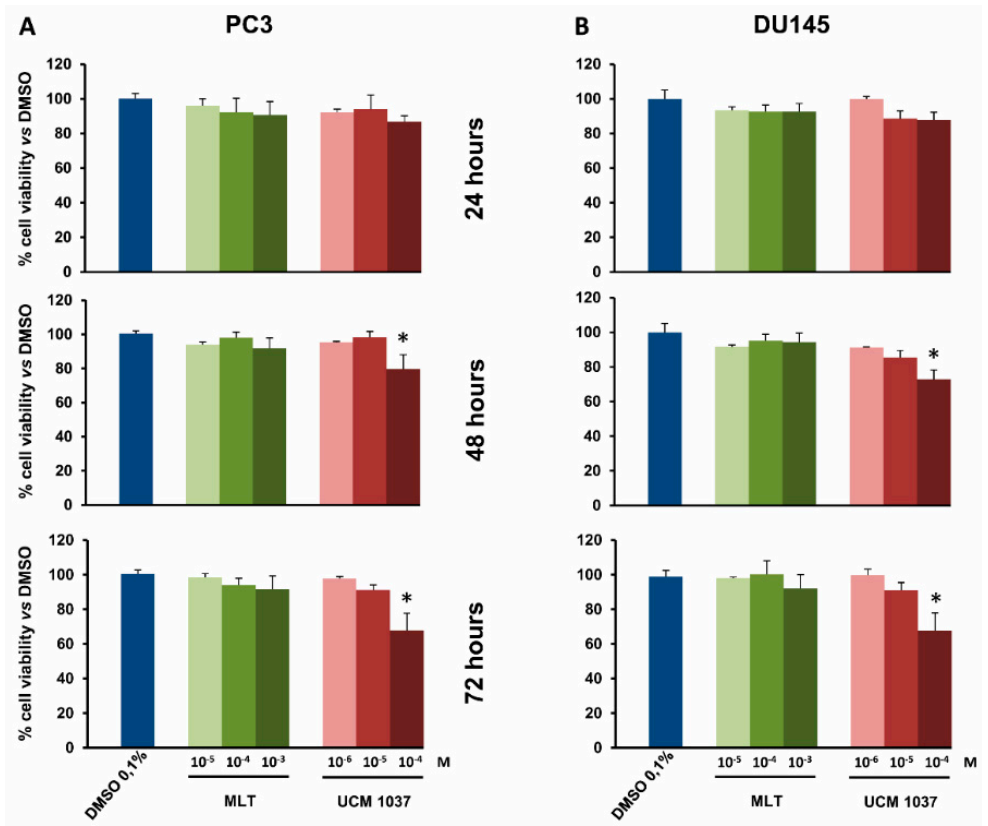

Figure 4. Cell viability of androgen-insensitive prostate cancer cells treated with melatonin and UCM 1037. PC3 and DU145 androgen-insensitive prostate cancer cells were treated with MLT or with UCM 1037 at the indicated doses expressed in molarity (M) as described in Materials and Methods. PC3 (A) and DU145 (B) cell viability was evaluated after 24, 48, and $72 \mathrm{~h}$. Graphic bars represent the percentage of viable cells in each sample. The results have been normalized to $0.1 \%$ DMSO-treated cells and are the means of three independent experiments \pm s.d. * $p$-value $<0.001$ versus $0.1 \%$ DMSO-treated cells. 


\subsection{Effects of Melatonin Analogue on Cell Cycle Distribution}

To analyze in more detail the antiproliferative effect of UCM 1037 melatonin analogue on prostate cancer cells, we studied the cell cycle distribution of LNCaP, PC3, DU145, and 22Rv1 cells after exposure to $10^{-3} \mathrm{M}$ melatonin or $10^{-4} \mathrm{M} \mathrm{UCM} 1037$ for 24, 48, and $72 \mathrm{~h}$. Cytofluorimetric analysis using propidium iodide (PI) staining revealed a significant and time-dependent accumulation of LNCaP and 22Rv1 cells in the sub-G1 region after UCM 1037 treatment (Figure 5), which is indicative of apoptosis and/or necrosis [18].
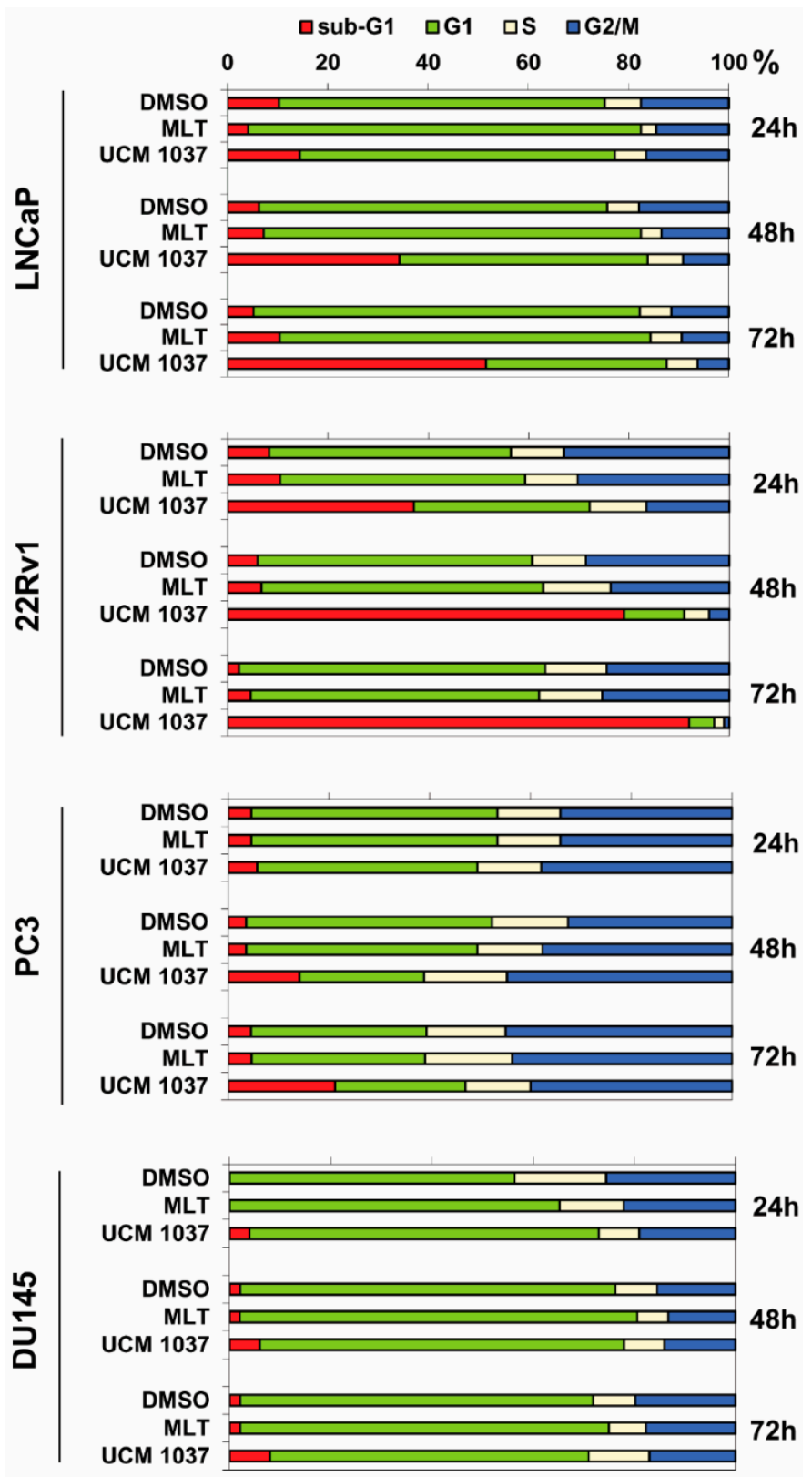

Figure 5. Cell cycle analysis in prostate cancer cells after treatment with melatonin and UCM 1037. LNCaP, 22Rv1, PC3, and DU145 prostate cancer cells were treated with $0.1 \%$ DMSO or with MLT $\left(10^{-3} \mathrm{M}\right)$ or with UCM $1037\left(10^{-4} \mathrm{M}\right)$ for 24,48 , and $72 \mathrm{~h}$, stained with PI, as indicated in the Materials and Methods, and then subjected to flow cytometric analysis. The bar graphs show the percentages of cells in sub-G1 region and G1, S, and G2/M phases. Data are representative of three independent experiments. 
UCM 1037 increased the sub-G1 fraction as a function of time in both $22 \mathrm{Rv} 1(37,79$, and $92 \%$ after 24,48 , and $72 \mathrm{~h}$, respectively) and $\operatorname{LNCaP}(14,34$, and $52 \%$ after 24,48 , and $72 \mathrm{~h}$, respectively) cells. In contrast, UCM 1037 only slightly increased the sub-G1 cell population in both PC3 and DU145 prostate cancer cells.

Consistent with the growth inhibitory effect observed in LNCaP, $1 \mathrm{mM}$ melatonin caused a transitory G1 accumulation with a concomitant depletion of $S$ and G2/M phases. Cell accumulation in G1 phase was at a maximum following $24 \mathrm{~h}$ of treatment $(78 \%$ in melatonin-treated versus $65 \%$ in control cells), lower by $48 \mathrm{~h}$ (75\% in melatonin-treated versus $69 \%$ in DMSO-treated cells), and after $72 \mathrm{~h}$ of incubation, the percentage of cells in G1 phase slightly declined below to control level $(74 \%$ in melatonin-treated versus 77\% in DMSO-treated cells). This transient G1 accumulation induced by melatonin was visible, although to a lesser extent, in DU145 cells.

In spite of growth inhibition induced by $1 \mathrm{mM}$ melatonin in 22Rv1 cells, no differences between untreated and melatonin-treated cells were observed, for any phases of the cell cycle.

As expected, the percentage of cells with hypodiploid DNA content (sub-G1) was similar in absence or in presence of $1 \mathrm{mM}$ melatonin, at all time points analyzed in all cell lines.

\subsection{Cytotoxicity of Melatonin Analogue on Prostate Cancer Cells}

Apoptosis was then analyzed using Annexin V assay, which enables the detection of apoptotic and necrotic cells by flow cytometry. All the human prostate cancer cell lines were exposed to $10^{-3} \mathrm{M}$ melatonin or $10^{-4} \mathrm{M}$ UCM 1037 for 24 to $72 \mathrm{~h}$ and subjected to Annexin V/PI staining. As shown in Figure 6 the distribution of cellular population on the Annexin V/PI cytograms was used to distinguish living cells (Annexin V-negative/PI-negative), early apoptotic cells (Annexin V-positive/PI-negative), late apoptotic cells (Annexin V-positive/PI-positive), and necrotic cells (Annexin V-negative/PI-positive). The percentage of LNCaP and 22Rv1 necrotic cells after UCM 1037 treatment for $24 \mathrm{~h}$ was approximately 9.5- and 8-fold that of the control cells, respectively (Figure 6A,B). The number of stained cells increased over time, indicating that $10^{-4} \mathrm{M} \mathrm{UCM} 1037$ had a conspicuous cytotoxic effect on androgen-sensitive prostate cancer cells. At the concentrations of $1 \mathrm{mM}$ melatonin, apoptotic LNCaP and 22Rv1 cells increased by 1.5- and 5-fold, respectively, compared to control cells, after 72 h (Figure 6A,B). Both UCM 1037 and melatonin cytotoxic effects were less evident in androgen-insensitive prostate cancer cells (Figure 6C,D).

\subsection{Melatonin Analogue Effects on AR and Akt Levels}

To identify the mechanisms underlying UCM 1037-mediated cytotoxicity in androgen-sensitive prostate cancer cells, AR and Akt expression was examined in LNCaP and 22Rv1 cells in a short-term time course (Figure 7). Western blot analysis showed that AR protein levels in UCM 1037 treated cells were significantly decreased in both LNCaP (Figure 7A) and 22Rv1 cells (Figure 7B). Using densitometric analysis, AR protein levels were quantified and normalized versus tubulin levels. The histograms shown in Figure 7 indicate that AR decreases to $7 \%$ and 38\% in UCM 1037 treated LNCaP and 22Rv1 cells, respectively, after $4 \mathrm{~h}$. No significant changes in AR levels were visible in DMSO-treated cells.

To determine if the melatonin analogue acted on the Akt pathway, Ser473 phosphorylated Akt (p-Akt) levels in LNCaP and 22Rv1 cells were determined. Western blot analysis showed that the melatonin analogue effectively decreased Akt phosphorylation in a time-dependent manner in UCM 1037 treated cells. Densitometric analysis revealed that p-Akt levels declined to 3\% and 16\% in LNCaP and 22Rv1 cells, respectively, $4 \mathrm{~h}$ after UCM 1037 treatment. No changes in total Akt levels were visible in both DMSO and UCM 1037 treated cells. 
A

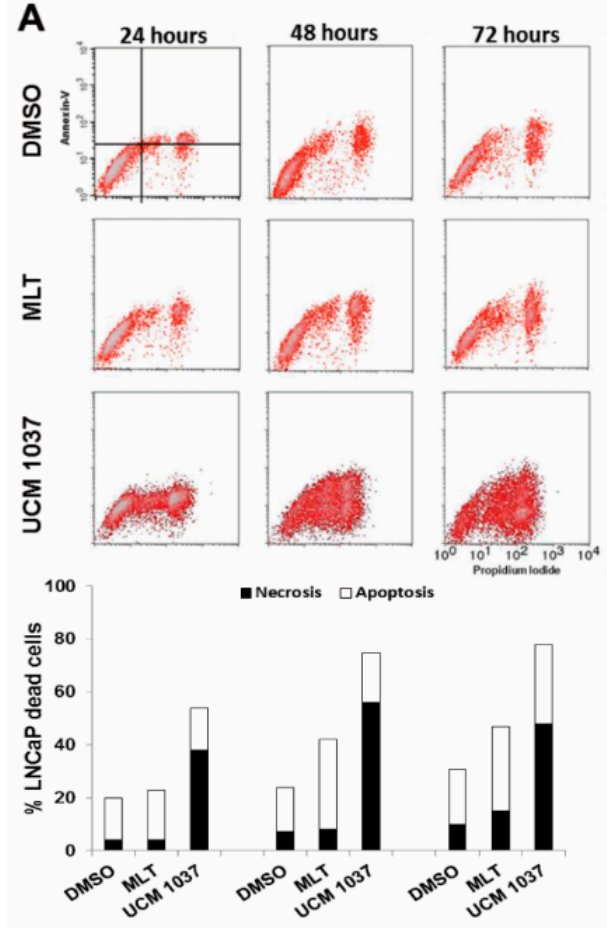

C
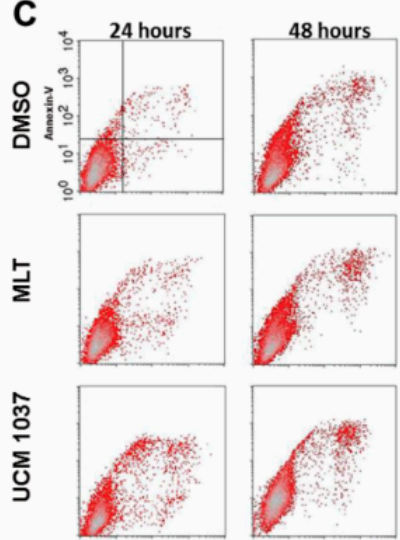

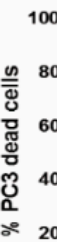

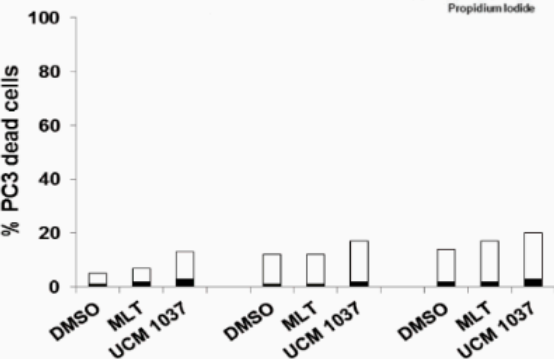

B

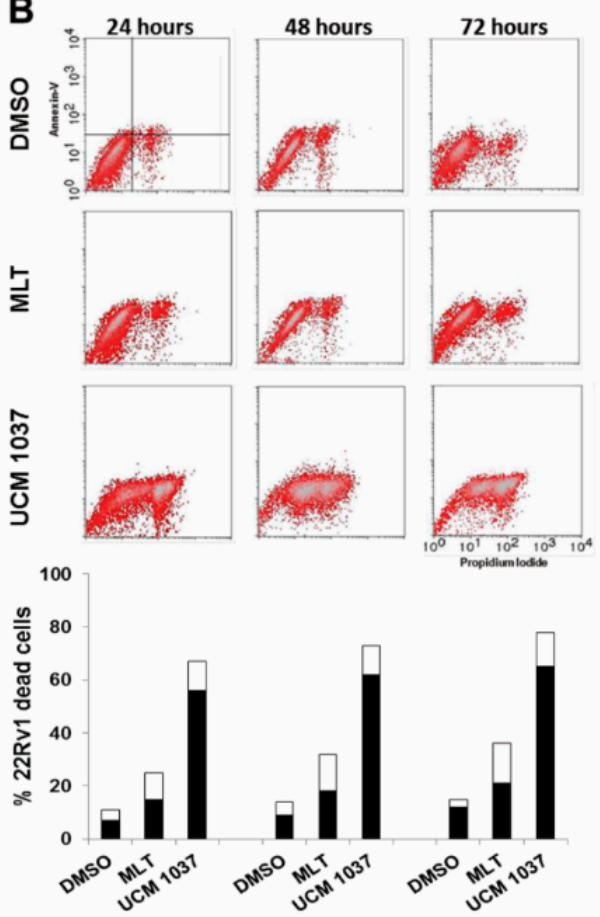

D
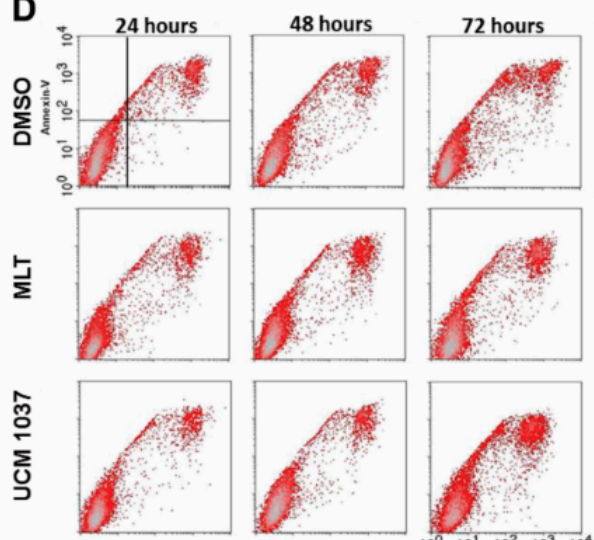

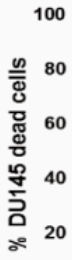
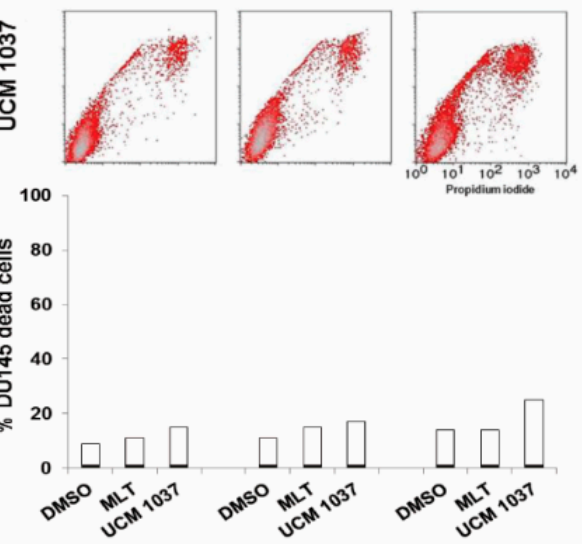

Figure 6. Apoptotic and necrotic cell determinations in prostate cancer cells treated with melatonin and UCM 1037. LNCaP (A), 22Rv1 (B), PC3 (C), and DU145 (D) cancer cells were treated with 0.1\% DMSO dissolved in culture medium or with melatonin $\left(10^{-3} \mathrm{M}\right)$ or with UCM $1037\left(10^{-4} \mathrm{M}\right)$ diluted in $0.1 \%$ DMSO. After 24, 48, and $72 \mathrm{~h}$ cells were simultaneously stained with Alexa Fluor-488-Annexin V and propidium iodide and analyzed by flow-cytometry to determine apoptosis and necrosis as described in the Materials and Methods. One representative experiment out of three performed with similar results is shown. For each panel the cytograms represent viable (Annexin V-negative/PI-negative), early apoptotic (Annexin V-positive/PI-negative), late apoptotic (Annexin V-positive/PI-positive), and necrotic (Annexin V-negative/PI-positive) cells. The bar graphs represent the percentage of early and late apoptotic cells (white bars) and necrotic cells-treated (black bars), as described above. 

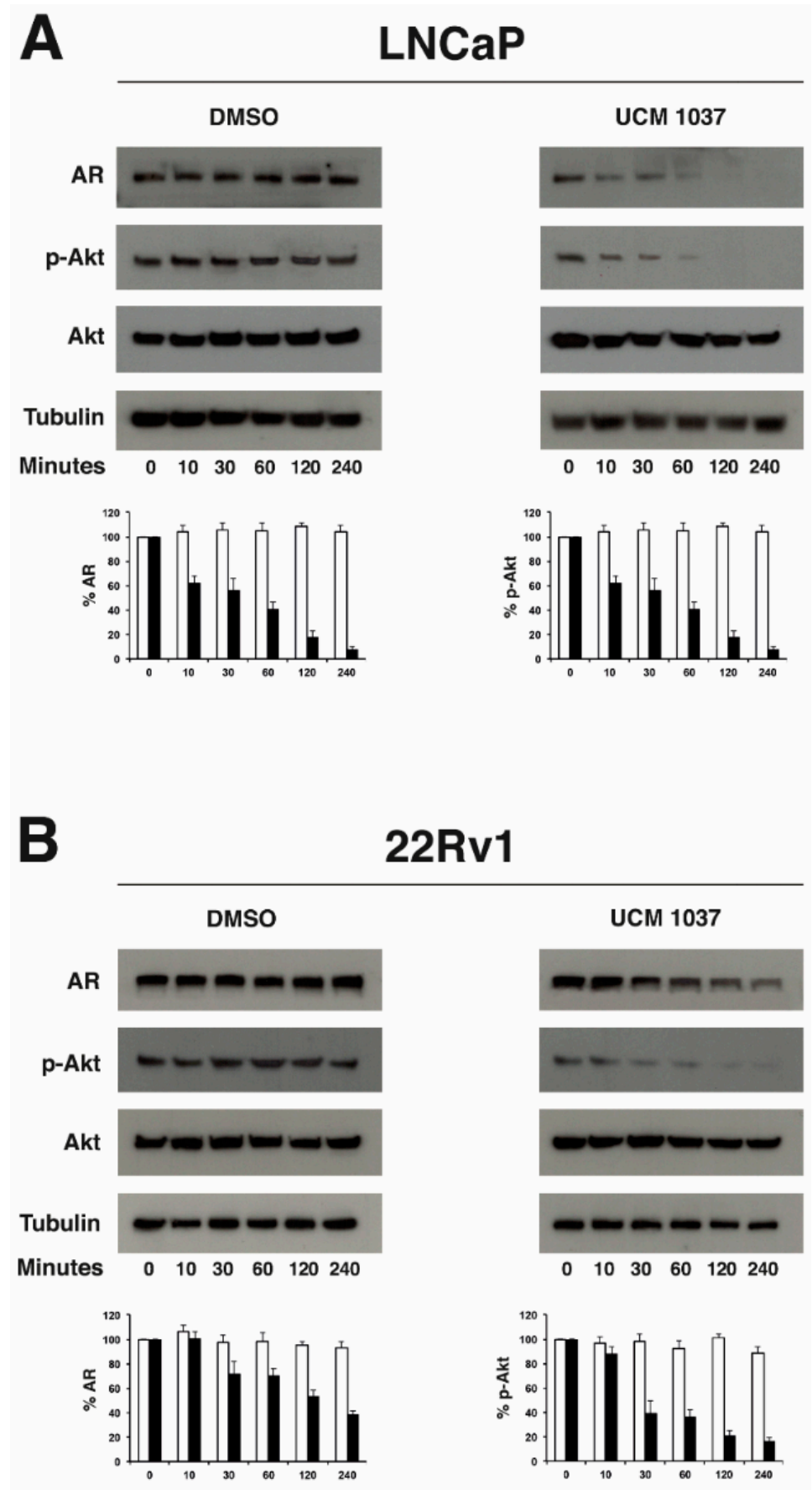

Figure 7. UCM 1037 reduces AR and p-Akt levels in androgen-sensitive prostate cancer cells. LNCaP (A) and 22Rv1 (B) prostate cancer cells were treated with $0.1 \%$ or with UCM $1037\left(10^{-4} \mathrm{M}\right)$ for 0,10 , $30,60,120$, and $240 \mathrm{~min}$ and then subjected to Western blot analysis. Blots are shown for AR, p-Akt, and Akt proteins with their corresponding tubulin controls. One representative blot is shown of three independent experiments. Bar charts show the quantification of AR and p-Akt in DMSO (white bars) and UCM 1037-treated cells (black bars). Densitometric data were normalized versus tubulin and the results are presented as the relative percentage of protein levels at $0 \mathrm{~h}$. Each bar represents the mean \pm s.d. of three independent experiments.

\section{Discussion}

Many studies suggest that natural bioactive compounds and their synthetic derivatives could be used in combination with traditional chemotherapeutic agents as potential anti-cancer therapies $[19,20]$. 
In this study, we employed a melatonin analogue and studied its role in cancer cell proliferation control and the ability to promote cell death in prostate cancer cells.

LNCaP, PC3, DU145, and 22Rv1 cell lines differ in several parameters, including androgen responsiveness and melatonin membrane receptor presence, and reflect a range of prostate cancer progression and androgen sensitivity, which make them excellent models to evaluate the antiproliferative role of melatonin and its derivatives, as well as the possible mechanisms involved.

Melatonin receptor expression has been demonstrated in many cancer types and activation of $\mathrm{MT}_{1}$ and $\mathrm{MT}_{2}$ receptors has been proposed to induce antiproliferative and pro-differentiating effects, as recently reviewed by Reiter et al. [7]. Here, we demonstrated the presence of G protein-coupled melatonin $\mathrm{MT}_{1}$ receptor in all the above mentioned human prostate cancer cell lines, although the membrane receptor levels greatly differ among them (Figure 2). $\mathrm{MT}_{1}$ receptor protein expression was previously detected in LNCaP, 22Rv1 and DU145 cells but not in PC3 cells by immunocytochemistry using purified anti- $\mathrm{MT}_{1}$ receptor serum [21]. On the contrary, we could establish that PC3 cells express melatonin $\mathrm{MT}_{1}$ membrane receptor protein, though to a low level. We also showed that the $\mathrm{MT}_{2}$ receptor, which is more restrictively expressed in human cell types and tissues, is present in androgen-insensitive DU145 and PC3 prostate cancer cells, but not in androgen-sensitive LNCaP and 22Rv1 cells.

It has been previously shown that melatonin inhibits the growth of LNCaP and 22Rv1 androgen-sensitive human prostate cancer cells and that the antiproliferative action of melatonin is mediated, at least partially, by $\mathrm{MT}_{1}$ activation [14,22]. Melatonin antiproliferative effects on PC3 and DU145 cells are more controversial: the indolic hormone was found to have no effects on the proliferation of androgen-insensitive PC3 and DU145 cells by Siu et al. [21], while others reported inhibitory actions of melatonin on PC3 and DU145 cell proliferation in vitro [23-25]. However, no effects of melatonin on the growth of DU145 and PC3 tumors was observed in nude mice [13].

We recently demonstrated that the melatonin receptor ligand UCM 1037 acts as a full agonist in both melatonin receptor subtypes and that this compound is effective in suppressing cancer cell growth of melanoma both in vitro and in vivo [17]. Although UCM 1037 antiproliferative activity could be attributed, at least in part, to the receptor-mediated actions of the melatonin derivative, the hypothesis that it may be modulated by the compound ability to interact with lipophilic compartments of the cells and / or be due to off targets could not be ruled out.

Here we evaluated the effects of the melatonin derivative UCM 1037 on cell proliferation in both androgen-sensitive and androgen-insensitive prostate cancer cells. According to the results of the cell viability assays, UCM 1037 demonstrated substantial dose- and time-dependent antiproliferative effects in androgen-sensitive LNCaP and 22Rv1 cells (Figure 3).

Interestingly, despite the high level of expression of the $\mathrm{MT}_{1}$ receptor in DU145 cells (Figure 2), UCM 1037 inhibited androgen-insensitive cell proliferation only at the $10^{-4} \mathrm{M}$ concentration, while melatonin did not elicit any significant effect in androgen-independent prostate cancer cells, thus confirming previously-obtained results [21]. Given that the $\mathrm{MT}_{1}$ receptor is considered to be responsible for the transduction of the antiproliferative signal of melatonin [13,22], it is possible that the altered $\mathrm{MT}_{1}$ receptor functions and/or interactions in androgen-insensitive PC3 and DU145 cells may account for the failure of melatonin antiproliferative signal transduction.

Overall, we observed that the melatonin derivative exerts antiproliferative effects on $\mathrm{MT}_{1}$-positive, $\mathrm{MT}_{2}$-negative androgen-sensitive prostate cancer cells. From these data we can infer that UCM 1037 activity on prostate cancer cell proliferation is $\mathrm{MT}_{2}$-independent, while $\mathrm{MT}_{1}$ expression is not sufficient to elicit this effect. We previously demonstrated that UCM 1037 induced significant inhibition of cell proliferation in NIH3T3-1A and NIH3T3-1B cell clones, expressing $\mathrm{MT}_{1}$ and $\mathrm{MT}_{2}$, respectively, compared to wild-type NIH3T3 cells [17]. These results indicated that the antiproliferative activity of the melatonin analogue is receptor-dependent and is possibly mediated by both melatonin receptors. However, the UCM 1037 mode of action is stringently cell line-dependent and receptor-independent effects can also be hypothesized. 
To further examine whether UCM 1037-induced cell growth inhibition is mediated via alterations in cell cycle progression, we analyzed the effects of the melatonin derivative on cell cycle phase distribution by flow cytometry. The decrease of LNCaP and 22Rv1 cell numbers due to the antiproliferative action of UCM 1037 resulted in induction of cell death, as demonstrated by the high percentage of cells with hypodiploid DNA content (sub-G1) accumulating over time.

The antiproliferative mechanism triggered by UCM 1037 in androgen-sensitive prostate cancer cells is, thus, quite different from melatonin-induced cell proliferation reduction. Indeed, data presented in this study, and previously reported by others, support a melatonin-induced cell growth inhibition mechanism independent of apoptosis induction, but rather reliant on cell accumulation in the G1 phase, in melanoma, breast, and prostate cancer cells [18,25-27].

Cytotoxicity induced by UCM 1037 in androgen-sensitive prostate cancer cells was further demonstrated by Annexin V binding combined with PI staining, which serves as a sensitive detection method of early and late stages of apoptosis, as well as necrosis. The percentage of LNCaP and 22Rv1 necrotic cells dramatically increased following UCM 1037 exposure, the apoptotic rate of 22Rv1 cells also augmented compared to DMSO-treated control cells, although to a lesser extent. On the contrary, the UCM 1037 cytotoxic effect was much less evident in androgen-insensitive prostate cancer cells. Taken together, the flow cytometry data presented herein suggest that UCM 1037 is highly cytotoxic to androgen-sensitive prostate cancer cells, although we did not observe a substantial increase in the apoptotic cell fraction, in contrast to what we observed in melanoma cells [17].

These findings prompted us to further investigate the effects of UCM 1037 in the signaling pathways involved in antiproliferative and cytotoxic actions of the melatonin derivative.

Recently, a functional link between the androgen receptor and melatonin signal transduction pathways has been envisaged. In particular, Zisapel's group demonstrated that melatonin induces nuclear exclusion of the AR via activation of protein kinase $C$ in androgen-insensitive prostate carcinoma PC3 cells stably transfected with a wild-type AR-expressing vector [28,29]. Moreover, knockdown of the expression of AR in LNCaP and 22Rv1 cells resulted in abrogation of melatonin receptor-mediated cell proliferation inhibition, indicating that the antiproliferative signaling pathway activated by melatonin in human prostate cancer cells is AR-dependent [30]. These data indicate the presence of a cross-talk between $\mathrm{MT}_{1}$ receptor and $\mathrm{AR}$ signaling in prostate cancer cells. However, melatonin actions are not limited to being merely anti-androgenic, as recently demonstrated by comparative genome microarray, melatonin-treated and androgen-deprived cells show many differentially expressed genes [31].

For these reasons we evaluated AR expression in UCM 1037-treated LNCaP and 22Rv1 cells and what we found was a remarkable down regulation of AR protein levels, which has never been observed before in melatonin-treated prostate cancer cells. These findings emphasize again that UCM 1037 and melatonin molecules elicit different responses on downstream signaling pathways.

Due to the lipophilic nature of UCM 1037 [17], receptor-independent effects could also be envisaged, with multiple signaling leading to modulation of different cascades. Several studies indicated that the PI3K/Akt cascade is associated with melatonin-mediated antiproliferative actions, although both stimulation [32,33] and inhibition [34-37] of phosphorylated Akt have been observed using different cell types.

We previously highlighted that the melatonin analogue UCM 1037, as well, can trigger and/or inhibit Akt phosphorylation differently in the cell lines examined: p-Akt increased in melanoma DX-3 cells, remained unaffected in melanoma WM-115 cells and dramatically decreased in breast cancer cell lines [17]. Here, we observed that UCM 1037 strongly inhibited Akt phosphorylation in androgen-sensitive prostate cancer.

Interestingly, a cross-talk between AR and Akt has been recently demonstrated in prostate cancer, whereby inhibition of Akt in cells expressing high levels of p-Akt resulted in decreased AR protein levels, overexpression of Akt resulted in increased levels of AR protein, while inhibition of low levels of endogenous Akt kinase activity did not affect AR protein levels [38]. 
According to the data presented here, p-Akt decrease paralleled AR reduction in LNCaP and $22 \mathrm{Rv} 1$ cells treated with UCM 1037, regardless of basal p-Akt levels. In fact, Akt phosphorylation is substantially up-regulated in PTEN-deficient LNCaP cells [39].

In view of the above, two not mutually exclusive scenarios can be considered to tentatively explain the molecular mechanisms underlying UCM 1037 antiproliferative and cytotoxic effects in androgen-sensitive prostate cancer cell lines: UCM 1037 may directly down-regulate AR and p-Akt levels, or AR down-regulation may be triggered by inhibition of Akt activation. However, the latter hypothesis alone would probably not suffice the almost simultaneous decrease in AR and p-Akt levels.

Although studies presented in this report did not examine $\mathrm{MT}_{1}$ 's role in mediating UCM 1037 effects, no correlation could be found between $\mathrm{MT}_{1}$ levels and the melatonin derivative antiproliferative and cytotoxic actions.

Mechanistically, we can conclude that UCM 1037 melatonin derivative inhibits androgen-sensitive prostate cancer cells growth, exerts a cytotoxic effect, down-regulates AR levels and Akt activation, possibly via a melatonin receptor-independent mechanism.

Together with the previous findings reported by this and other laboratories, data presented here on melatonin analogue anticancer effects may have significant implications on future clinical exploitation of these molecules in prostate cancer therapeutics.

\section{Materials and Methods}

\subsection{Cells Culture and Reagents}

The human prostate cancer cell line LNCaP [40], obtained from ICLC (Genova, Italy), was maintained in RPMI 1640 medium (Euroclone, Milan, Italy) supplemented with $20 \%$ FCS (Fetalclone I, Hyclone, Logan, UT, USA), $2 \mathrm{mM} \mathrm{L-glutamine,} 100 \mathrm{U} / 100 \mu \mathrm{g} / \mathrm{mL}$ penicillin/streptomycin (Sigma-Aldrich, Milan, Italy), 10 mM HEPES (Sigma-Aldrich). PC3 [41], and DU145 [42], obtained from Dr. N. Zaffaroni (Fondazione IRCCS Istituto Nazionale Tumori, Milan, Italy), and 22Rv1 [43], obtained from ATCC (Manassas, VA, USA) human prostate cell lines were maintained in RPMI 1640 medium supplemented with 10\% FCS, $2 \mathrm{mM}$ L-glutamine, $100 \mathrm{U} / 100 \mathrm{\mu g} / \mathrm{mL}$ penicillin/streptomycin solution. All cell lines were maintained at $37^{\circ} \mathrm{C}$ and $5 \% \mathrm{CO}_{2}$. Melatonin was purchased from Sigma-Aldrich and UCM 1037 was kindly provided by Dr. G. Spadoni (University of Urbino, Italy).

\subsection{Cellular Proliferation and Viability Assay}

LNCaP, 22Rv1 $\left(4 \times 10^{3} /\right.$ well), PC3 and DU145 $\left(2 \times 10^{3} /\right.$ well $)$ cells were seeded in 96-well plates and incubated at $37{ }^{\circ} \mathrm{C}$ with a $5 \% \mathrm{CO}_{2}$ humidified atmosphere. $24 \mathrm{~h}$ later, cells were treated with $0.1 \%$ DMSO dissolved in culture medium or with different doses of melatonin and UCM 1037 diluted in $0.1 \%$ DMSO and cultured for 24,48 , and $72 \mathrm{~h}$.

The cell viability and proliferation were assayed using the Cell Counting Kit-8 (Dojindo Laboratories, Japan), according to the manufacturer's protocol. Briefly, cells were incubated for four hours with freshly prepared WST-8 solution (10 $\mu \mathrm{L} /$ well) and then the number of viable cells was assessed by measuring the absorbance at $450 \mathrm{~nm}$, using a Wallac Victor 1420 Multilabel Counter (Perkin Elmer, MA, USA). The experiments were performed in quadruplicate and repeated three times.

\subsection{Cell Cycle Analysis by Flow Cytometry}

LNCaP, 22Rv1 $\left(5 \times 10^{5}\right)$, PC3 and DU145 $\left(3 \times 10^{5}\right)$ cells were seeded in 60-mm plates and $24 \mathrm{~h}$ later they were treated with $0.1 \%$ DMSO dissolved in culture medium or with melatonin $\left(10^{-3} \mathrm{M}\right)$ or with UCM $1037\left(10^{-4} \mathrm{M}\right)$ diluted in $0.1 \%$ DMSO. After 24,48 , and $72 \mathrm{~h}$ cells were collected, washed, and stained for $30 \mathrm{~min}$ at $37^{\circ} \mathrm{C}$ with $1 \mathrm{~mL}$ of DNA-staining solution in $0.1 \%$ Nonidet P-40 (Sigma-Aldrich, Milan, Italy), $0.5 \mathrm{mg} / \mathrm{mL}$ RNAse (type IIIA, Sigma-Aldrich), and $25 \mu \mathrm{g} / \mathrm{mL}$ propidium iodide (Sigma-Aldrich) [44]. The cellular DNA content was analyzed by FACScalibur (Becton Dickinson 
Immunocytometry Systems, San Jose, CA, USA) using a Cell Quest (Becton Dickinson) software system for histograms of propidium iodide fluorescence intensity vs. cell frequency.

\subsection{Detection of Apoptosis and Necrosis by Annexin-V/Propidium Iodide Assay}

LNCaP, 22Rv1 $\left(5 \times 10^{5}\right)$, PC3, and DU145 $\left(3 \times 10^{5}\right)$ cells were seeded in 60-mm plates and incubated at $37{ }^{\circ} \mathrm{C}$ with a $5 \% \mathrm{CO}_{2}$ humidified atmosphere. $24 \mathrm{~h}$ later, cells were treated with $0.1 \%$ DMSO dissolved in culture medium or with melatonin $\left(10^{-3} \mathrm{M}\right)$ or with UCM $1037\left(10^{-4} \mathrm{M}\right)$ diluted in $0.1 \%$ DMSO. After 24, 48, and $72 \mathrm{~h}$ cells were simultaneously stained with Alexa Fluor 488-conjugated Annexin-V and PI, using the Vybrant Apoptosis Assay kit \#2 (Molecular Probes, Eugene, OR, USA), according to the manufacturer's instructions. Samples were analyzed by FACScalibur flow cytometer (Becton Dickinson). In each analysis 10,000 events were recorded and the percentage of apoptotic cells estimated by means of the CellQuest Pro software (Becton Dickinson). The simultaneous staining of cells with Annexin-V and PI allowed the resolution of viable cells (Annexin V-negative/PI-negative), early apoptotic cells (Annexin V-positive/PI-negative), necrotic cells (Annexin V-negative/PI-positive), and late apoptotic cells (Annexin V-positive/PI-positive).

\subsection{Western Blot Analysis}

LNCaP and 22Rv1 cells were plated onto $60-\mathrm{mm}$ dishes at a density of $5 \times 10^{5}$ cells $/ \mathrm{mL}$ and incubated at $37^{\circ} \mathrm{C}$ with $5 \% \mathrm{CO}_{2}$ humidified atmosphere. Twenty-four hours later, cells were treated with $0.1 \%$ DMSO dissolved in culture medium or with $10^{-4}$ M UCM 1037 diluted in $0.1 \%$ DMSO and cultured for 10, 30, 60, 120, and $240 \mathrm{~min}$, then harvested. Cells were collected by centrifugation at $1000 \mathrm{rpm}$ for $10 \mathrm{~min}$, washed with cold PBS, resuspended in lysis buffer (50 mM Hepes- $\mathrm{NaOH}$, pH 7.5, $150 \mathrm{mM} \mathrm{NaCl}, 15 \mathrm{mM} \mathrm{MgCl} 2,1 \mathrm{mM}$ EGTA-NaOH pH 7.5, 1\% Triton X-100, 1 mM sodium orthovanadate, $1 \mathrm{mM}$ phenylmethylsulfonyl fluoride, and $10 \mu \mathrm{g} / \mathrm{mL}$ of leupeptin, aprotinin, antipain, and chymostatin) and incubated on ice for $45 \mathrm{~min}$. The lysates were centrifuged at 13,000 rpm for $10 \mathrm{~min}$ at $4{ }^{\circ} \mathrm{C}$. Equivalent amounts of proteins were analyzed by SDS-polyacrylamide gel electrophoresis. After electrophoretic separation, the proteins were transferred onto nitrocellulose membrane (GE Healthcare, Pittsburg, PA, USA). After $1 \mathrm{~h}$ of incubation in blocking solution ( $\%$ milk in PBS $/ 0,1 \%$ Tween), filters were incubated with the appropriate antibodies: $\mathrm{MT}_{1}, \mathrm{MT}_{2}$ (Biorbyt, San Francisco, CA, USA), Ser473 phosphorylated Akt (p-Akt), Akt, Androgen Receptor (Cell Signaling Technology, Danvers, MA, USA) and $\beta$-Tubulin (Sigma-Aldrich). Proteins were visualized with peroxidase-coupled secondary antibody (GE Healthcare), using enhanced chemiluminescence (ECL) for detection (GE Healthcare). Densitometry was performed on scanned immunoblot images using the NIH ImageJ software (NIH, Bethesda, MA, USA).

\subsection{Statistical Analysis}

Data are the mean \pm standard deviation of at least three independent experiments and were evaluated by Student's $t$-test. Values of $p<0.001$ were considered statistically significant.

Author Contributions: A.B., G.C. and F.S. conceived and designed the experiments; A.C., G.G., V.L. and S.D. performed the experiments; A.B., A.C., G.G., V.L. and S.D. analyzed the data; G.C. and F.S. contributed reagents and materials; A.B. wrote the paper; and A.C., G.G., G.C. and F.S. reviewed the paper.

Acknowledgments: A.B. is supported by a grant from Fondazione Cariplo-Regione Lombardia (grant No. 2016-1022).

Conflicts of Interest: The authors declare no conflict of interest.

\section{References}

1. Pandi-Perumal, S.R.; Srinivasan, V.; Maestroni, G.J.; Cardinali, D.P.; Poeggeler, B.; Hardeland, R. Melatonin: Nature's most versatile biological signal? FEBS J. 2006, 273, 2813-2838. [CrossRef] [PubMed] 
2. Hardeland, R.; Cardinali, D.P.; Srinivasan, V.; Spence, D.W.; Brown, G.M.; Pandi-Perumal, S.R. Melatonin-A pleiotropic, orchestrating regulator molecule. Prog. Neurobiol. 2011, 93, 350-384. [CrossRef] [PubMed]

3. Acuña-Castroviejo, D.; Escames, G.; Venegas, C.; Díaz-Casado, M.E.; Lima-Cabello, E.; López, L.C.; Rosales-Corral, S.; Tan, D.; Reiter, R.J. Extrapineal melatonin: Sources, regulation, and potential functions. Cell. Mol. Life Sci. 2014, 71, 2997-3025. [CrossRef] [PubMed]

4. Li, Y.; Li, S.; Zhou, Y.; Meng, X.; Zhang, J.J.; Xu, D.P.; Li, H.B. Melatonin for the prevention and treatment of cancer. Oncotarget 2017, 8, 39896-39921. [CrossRef] [PubMed]

5. Sigurdardottir, L.G.; Markt, S.C.; Rider, J.R.; Haneuse, S.; Fall, K.; Schernhammer, E.S.; Tamimi, R.M.; Flynn-Evans, E.; Batista, J.L.; Launer, L.; et al. Urinary Melatonin Levels, Sleep Disruption, and Risk of Prostate Cancer in Elderly Men. Eur. Urol. 2015, 67, 191-194. [CrossRef] [PubMed]

6. Tai, S.Y.; Huang, S.P.; Bao, B.Y.; Wu, M.T. Urinary melatonin-sulfate/cortisol ratio and the presence of prostate cancer: A case-control study. Sci. Rep. 2016, 8, 29606. [CrossRef] [PubMed]

7. Reiter, R.J.; Rosales-Corral, S.A.; Tan, D.X.; Acuna-Castroviejo, D.; Qin, L.; Yang, S.F.; Xu, K. Melatonin, a Full Service Anti-Cancer Agent: Inhibition of Initiation, Progression and Metastasis. Int. J. Mol. Sci. 2017, $18,843$. [CrossRef] [PubMed]

8. Dubocovich, M.L.; Markowska, M. Functional MT1 and MT2 melatonin receptors in mammals. Endocrine 2005, 27, 101-110. [CrossRef]

9. Pandi-Perumal, S.R.; Trakht, I.; Srinivasan, V.; Spence, D.W.; Maestroni, G.J.; Zisapel, N.; Cardinali, D.P. Physiological effects of melatonin: Role of melatonin receptors and signal transduction pathways. Prog. Neurobiol. 2008, 85, 335-353. [CrossRef] [PubMed]

10. Boutin, J.A.; Audinot, V.; Ferry, G.; Delagrange, P. Molecular tools to study melatonin pathways and actions. Trends Pharmacol. Sci. 2005, 26, 412-419. [CrossRef] [PubMed]

11. Luchetti, F.; Canonico, B.; Betti, M.; Arcangeletti, M.; Pilolli, F.; Piroddi, M.; Canesi, L.; Papa, S.; Galli, F. Melatonin signaling and cell protection function. FASEB J. 2010, 24, 3603-3624. [CrossRef] [PubMed]

12. Slominski, R.M.; Reiter, R.J.; Schlabritz-Loutsevitch, N.; Ostrom, R.S.; Slominski, A.T. Melatonin membrane receptors in peripheral tissues: Distribution and functions. Mol. Cell. Endocrinol. 2012, 351, 152-166. [CrossRef] [PubMed]

13. Xi, S.C.; Siu, S.W.; Fong, S.W.; Shiu, S.Y. Inhibition of androgen-sensitive LNCaP prostate cancer growth in vivo by melatonin: Association of antiproliferative action of the pineal hormone with $\mathrm{mt} 1$ receptor protein expression. Prostate 2001, 46, 52-61. [CrossRef]

14. Tam, C.W.; Mo, C.W.; Yao, K.M.; Shiu, S.Y. Signaling mechanisms of melatonin in antiproliferation of hormone-refractory 22Rv1 human prostate cancer cells: Implications for prostate cancer chemoprevention. J. Pineal Res. 2007, 42, 191-202. [CrossRef] [PubMed]

15. Mao, L.; Cheng, Q.; Guardiola-Lemaître, B.; Schuster-Klein, C.; Dong, C.; Lai, L.; Hill, S.M. In vitro and in vivo antitumor activity of melatonin receptor agonists. J. Pineal Res. 2010, 49, 210-221. [CrossRef] [PubMed]

16. Zlotos, D.P.; Jockers, R.; Cecon, E.; Rivara, S.; Witt-Enderby, P.A. MT1 and MT2 Melatonin Receptors: Ligands, Models, Oligomers, and Therapeutic Potential. J. Med. Chem. 2014, 57, 3161-3185. [CrossRef] [PubMed]

17. Gatti, G.; Lucini, V.; Dugnani, S.; Calastretti, A.; Spadoni, G.; Bedini, A.; Rivara, S.; Mor, M.; Canti, G.; Scaglione, F.; et al. Antiproliferative and pro-apoptotic activity of melatonin analogues on melanoma and breast cancer cells. Oncotarget 2017, 8, 68338-68353. [CrossRef] [PubMed]

18. Ormerod, M.G. Investigating the relationship between the cell cycle and apoptosis using flow cytometry. J. Immunol. Methods 2002, 265, 73-80. [CrossRef]

19. Rodriguez-Garcia, A.; Hevia, D.; Mayo, J.C.; Gonzalez-Menendez, P.; Coppo, L.; Lu, J.; Holmgren, A.; Sainz, R.M. Thioredoxin 1 modulates apoptosis induced by bioactive compounds in prostate cancer cells. Redox Biol. 2017, 12, 634-647. [CrossRef] [PubMed]

20. Wang, Z.; Fan, J.; Liu, M.; Yeung, S.; Chang, A.; Chow, M.S.; Pon, D.; Huang, Y. Nutraceuticals for prostate cancer chemoprevention: From molecular mechanisms to clinical application. Expert Opin. Investig. Drugs 2013, 22, 1613-1626. [CrossRef] [PubMed]

21. Siu, S.W.; Lau, K.W.; Tam, P.C.; Shiu, S.Y. Melatonin and prostate cancer cell proliferation: Interplay with castration, epidermal growth factor, and androgen sensitivity. Prostate 2002, 52, 106-122. [CrossRef] [PubMed] 
22. Xi, S.C.; Tam, P.C.; Brown, G.M.; Pang, S.F.; Shiu, S.Y. Potential involvement of $\mathrm{mt} 1$ receptor and attenuated sex steroid-induced calcium influx in the direct anti-proliferative action of melatonin on androgen-responsive LNCaP human prostate cancer cells. J. Pineal Res. 2000, 29, 172-183. [CrossRef] [PubMed]

23. Gilad, E.; Laufer, M.; Matzkin, H.; Zisapel, N. Melatonin receptors in PC3 human prostate tumor cells. J. Pineal Res. 1999, 26, 211-220. [CrossRef] [PubMed]

24. Marelli, M.M.; Limonta, P.; Maggi, R.; Motta, M.; Moretti, R.M. Growth-inhibitory activity of melatonin on human androgen-independent DU145 prostate cancer cells. Prostate 2000, 45, 238-244. [CrossRef]

25. Sainz, R.M.; Mayo, J.C.; Tan, D.X.; León, J.; Manchester, L.; Reiter, R.J. Melatonin reduces prostate cancer cell growth leading to neuroendocrine differentiation via a receptor and PKA independent mechanism. Prostate 2005, 63, 29-43. [CrossRef] [PubMed]

26. Cabrera, J.; Negrín, G.; Estévez, F.; Loro, J.; Reiter, R.J.; Quintana, J. Melatonin decreases cell proliferation and induces melanogenesis in human melanoma SK-MEL-1 cells. J. Pineal Res. 2010, 49, 45-54. [CrossRef] [PubMed]

27. Cos, S.; Recio, J.; Sánchez-Barceló, E.J. Modulation of the length of the cell cycle time of MCF-7 human breast cancer cells by melatonin. Life Sci. 1996, 58, 811-816. [CrossRef]

28. Rimler, A.; Culig, Z.; Lupowitz, Z.; Zisapel, N. Nuclear exclusion of the androgen receptor by melatonin. J. Steroid Biochem. Mol. Biol. 2002, 81, 77-84. [CrossRef]

29. Sampson, S.R.; Lupowitz, Z.; Braiman, L.; Zisapel, N. Role of protein kinase Calpha in melatonin signal transduction. Mol. Cell. Endocrinol. 2006, 252, 82-87. [CrossRef] [PubMed]

30. Tam, C.W.; Shiu, S. Functional interplay between melatonin receptor-mediated antiproliferative signaling and androgen receptor signaling in human prostate epithelial cells: Potential implications for therapeutic strategies against prostate cancer. J. Pineal Res. 2011, 51, 297-312. [CrossRef] [PubMed]

31. Mayo, J.C.; Hevia, D.; Quiros-Gonzalez, I.; Rodriguez-Garcia, A.; Gonzalez-Menendez, P.; Cepas, V.; Gonzalez-Pola, I.; Sainz, R.M. IGFBP3 and MAPK/ERK signaling mediates melatonin-induced antitumor activity in prostate cancer. J. Pineal Res. 2017, 62. [CrossRef] [PubMed]

32. An, R.; Zhao, L.; Xi, C.; Li, H.; Shen, G.; Liu, H.; Zhang, S.; Sun, L. Melatonin attenuates sepsis-induced cardiac dysfunction via a PI3K/Akt-dependent mechanism. Basic Res. Cardiol. 2016, 111, 8. [CrossRef] [PubMed]

33. Zhang, Y.; Wei, Z.; Liu, W.; Wang, J.; He, X.; Huang, H.; Zhang, J.; Yang, Z. Melatonin protects against arsenic trioxide-induced liver injury by the upregulation of Nrf2 expression through the activation of PI3K/AKT pathway. Oncotarget 2017, 8, 3773-3780. [CrossRef] [PubMed]

34. Fan, L.; Sun, G.; Ma, T.; Zhong, F.; Wei, W. Melatonin overcomes apoptosis resistance in human hepatocellular carcinoma by targeting survivin and XIAP. J. Pineal Res. 2013, 55, 174-183. [CrossRef] [PubMed]

35. Lu, Y.X.; Chen, D.L.; Wang, D.S.; Chen, L.Z.; Mo, H.Y.; Sheng, H.; Bai, L.; Wu, Q.N.; Yu, H.E.; Xie, D.; et al. Melatonin enhances sensitivity to fluorouracil in oesophageal squamous cell carcinoma through inhibition of Erk and Akt pathway. Cell Death Dis. 2016, 7, e2432. [CrossRef] [PubMed]

36. Proietti, S.; Cucina, A.; D'Anselmi, F.; Dinicola, S.; Pasqualato, A.; Lisi, E.; Bizzarri, M. Melatonin and vitamin D3 synergistically down-regulate Akt and MDM2 leading to TGF $\beta$-1-dependent growth inhibition of breast cancer cells. J. Pineal Res. 2011, 50, 150-158. [CrossRef] [PubMed]

37. Song, J.; Ma, S.J.; Luo, J.H.; Zhang, H.; Wang, R.X.; Liu, H.; Li, L.; Zhang, Z.G.; Zhou, R.X. Melatonin induces the apoptosis and inhibits the proliferation of human gastric cancer cells via blockade of the AKT/MDM2 pathway. Oncol. Rep. 2018, 39, 1975-1983. [CrossRef] [PubMed]

38. Ha, S.; Ruoff, R.; Kahoud, N.; Franke, T.F.; Logan, S.K. Androgen receptor levels are upregulated by Akt in prostate cancer. Endocr. Relat. Cancer 2011, 18, 245-255. [CrossRef] [PubMed]

39. Calastretti, A.; Gatti, G.; Quaresmini, C.; Bevilacqua, A. Down-modulation of Bcl-2 sensitizes PTEN-mutated prostate cancer cells to starvation and taxanes. Prostate 2014, 74, 1411-1422. [CrossRef] [PubMed]

40. Horoszewicz, J.S.; Leong, S.S.; Kawinski, E.; Karr, J.P.; Rosenthal, H.; Chu, T.M.; Mirand, E.A.; Murphy, G.P. LNCaP model of human prostatic carcinoma. Cancer Res. 1983, 43, 1809-1818. [PubMed]

41. Kaighn, M.E.; Narayan, K.S.; Ohnuki, Y.; Lechner, J.F.; Jones, L.W. Establishment and characterization of a human prostatic carcinoma cell line (PC-3). Investig. Urol. 1979, 17, 16-23.

42. Stone, K.R.; Mickey, D.D.; Wunderli, H.; Mickey, G.H.; Paulson, D.F. Isolation of a human prostate carcinoma cell line (DU 145). Int. J. Cancer 1978, 21, 274-281. [CrossRef] [PubMed] 
43. Sramkoski, R.M.; Pretlow, T.G., 2nd; Giaconia, J.M.; Pretlow, T.P.; Schwartz, S.; Sy, M.S.; Marengo, S.R.; Rhim, J.S.; Zhang, D.; Jacobberger, J.W. A new human prostate carcinoma cell line, 22Rv1. In Vitro Cell. Dev. Biol. Anim. 1999, 35, 403-409. [CrossRef] [PubMed]

44. Nicoletti, I.; Migliorati, G.; Pagliacci, M.C.; Grignani, F.; Riccardi, C. A rapid and simple method for measuring thymocyte apoptosis by propidium iodide staining and flow cytometry. J. Immunol. Methods 1991, 139, 271-279. [CrossRef] 